\title{
Institute of Medical Ethics Guidelines for confirmation of appointment, promotion and recognition of UK bioethics and medical ethics researchers
}

\author{
Lucy Frith, ${ }^{1}$ Carwyn Hooper, ${ }^{2}$ Silvia Camporesi, ${ }^{3}$ Thomas Douglas, $^{4}$ Anna Smajdor, ${ }^{5}$ \\ Emma Nottingham, ${ }^{6}$ Zoe Fritz, ${ }^{7}$ Merryn Ekberg, ${ }^{8}$ Richard Huxtable, ${ }^{9}$ on behalf the \\ Institute of Medical Ethics
}

${ }^{1}$ Department of Health Services

Research, University of

Liverpool, Liverpool, UK

${ }^{2}$ St George's, University of

London, London, UK

${ }^{3}$ Department of Social Science

Health \& Medicine, King's

College London, London, UK

${ }^{4}$ Oxford Uehiro Centre for

Practical Ethics, University of

Oxford, Oxford, UK

University of Oslo, Oslo,

Norway

${ }^{6}$ Law Department, University of Winchester, Winchester, UK

${ }^{7}$ Department of Acute Medicine,

Warwick university, and

Cambridge University Hospitals,

Cambridge, UK

${ }^{8}$ The University of Northampton,

Northamptonshire, UK

${ }^{9}$ Centre for Ethics in Medicine,

University of Bristol, School of

Social and Community Medicine,

Bristol, UK

Correspondence to

Dr Lucy Frith, Department of

Health Services Research, The

University of Liverpool, Liverpool

L69 3GL, UK ;

L.J.Frith@liverpool.ac.uk

Received 19 February 2018

Accepted 26 February 2018

Published Online First

23 March 2018

\section{ABSTRACT}

This document is designed to give guidance on assessing researchers in bioethics/medical ethics. It is intended to assist members of selection, confirmation and promotion committees, who are required to assess those conducting bioethics research when they are not from a similar disciplinary background. It does not attempt to give guidance on the quality of bioethics research, as this is a matter for peer assessment. Rather it aims to give an indication of the type, scope and amount of research that is the expected in this field. It does not cover the assessment of other activities such as teaching, policy work, clinical ethics consultation and so on, but these will be mentioned for additional context. Although it mentions the UK's Research Excellence Framework (REF), it is not intended to be a detailed analysis of the place of bioethics in the REF.

\section{SCOPE}

This document is designed to give guidance on assessing researchers in bioethics/medical ethics. ${ }^{\mathrm{i}} \mathrm{It}$ is intended to assist members of selection, confirmation and promotion committees (panels), who are required to assess those conducting bioethics research when they are not from a similar disciplinary background to the person being assessed. It does not attempt to give guidance on the quality of bioethics research, as this is a matter for peer assessment. ${ }^{\text {ii }}$ Rather it aims to give an indication of the type, scope and amount of research that is expected in this field. It does not cover the assessment of other activities such as teaching, policy work, clinical ethics consultation and so on, but these will be mentioned for additional context. Although it mentions the UK's Research Excellence Framework (REF), it is not intended to be a detailed analysis of the place of bioethics in the REF.

\section{BACKGROUND}

In the last 30 years, there has been an increase in the number of academics employed in the area of bioethics. Bioethics lies at the intersection of a number

\section{Check for updates}

To cite: Frith L, Hooper C, Camporesi $S$, et al.

$J$ Med Ethics

2018:44:289-291
'We will use the term 'bioethics' to include 'medical ethics', that is, to encompass work addressing ethical issues raised by the practice of medicine and the life sciences.

ii This would also be a topic too complex to cover in this brief document and has been the subject of extensive academic debate. of different disciplines. Its methods are chiefly those of philosophy and the social sciences, and it has application to medicine, science, law and public policy. As a result, academics in this area are based in a variety of academic faculties (eg, medical, humanities, social sciences, theology and law).

The interdisciplinary and rapidly developing nature of bioethics presents challenges to how bioethics researchers are judged by promotion and selection panels. This can lead to the value of this type of research being overlooked and researchers judged against inappropriate criteria. In response to this problem, in 2009 the American Society for Bioethics and Humanities (ASBH) published guidelines for tenure and promotion in academic medical centres for bioethics and medical humanities scholars. ${ }^{\text {iii }}$

The Institute of Medical Ethics is a membership organisation that represents those who predominately work in the area of bioethics, conducting research and teaching biomedical ethics to a variety of students. It is felt that a statement of guidance for panels on the criteria for judging an appropriate level and form of research output for researchers in this area, with a specific focus on researchers based in the $\mathrm{UK}$, is now needed.

\section{BIOETHICS}

\section{Research methods}

The primary methodology for bioethics is normative conceptual analysis. By 'normative', we mean providing practical recommendations for actions in response to 'ought-type' questions, for example, 'How ought we to use a certain technology?' Since the early 2000s, there has been a trend in bioethics towards more empirically focused research, where data, often qualitative, are collected, and the development of 'empirical ethics', in which ethical analysis directly engages with empirical data. However, purely conceptual or normative research remains core to the development of the discipline, and even when partly empirical, research in bioethics is rarely laboratory based and seldom involves the

\footnotetext{
iii Association of Bioethics Program Directors, Assessing the accomplishments of bioethics and medical humanities faculty members being considered for promotion or tenure in academic health centers (American Society for Bioethics and Humanities, October 2008). Available at: http://asbh.org/uploads/publications/Guidelines_for Tenure and Promotion.pdf.
} 
collection of large datasets (unless it is part of a larger research project).

\section{Type of discipline/disciplinary provenance}

Bioethicists can be drawn from a number of disciplines (eg, philosophy, law, social science, medical humanities) and research in this area is often an interdisciplinary endeavour. The debate over whether bioethics is a discipline in its own right is ongoing, but due to the institutional organisation of bioethics, researchers usually come from another 'home' discipline.

\section{Related activities}

Bioethics, as an applied discipline, is concerned with improving and influencing policy and practice and as such, bioethicists often sit on policy committees, research ethics committees and may have a number of advisory, consultancy and service roles with governmental and non-governmental agencies, charities and patient groups. Bioethicists also engage with broader public audiences and are often key contributors to their university's public engagement and involvement agendas.

\section{RECOMMENDATIONS}

\section{Research Excellence Framework}

The REF can create issues for bioethicists in finding a home for their research. Philosophy departments in many UK universities have not been eager to include bioethics work in their REF submissions, since the applied and sometimes interdisciplinary nature do not fully address the theoretical concerns that are seen as the core focus of philosophy. Social sciences departments that include bioethicists have sometimes struggled to include them in the REF as bioethics research may not be empirical enough or adequately informed by social theory. Public Health, Health Services and Primary Care Panel (UoA 2) $)^{\text {iv }}$ have not seen outputs in this area as conforming to what they think of as research (for instance, not valuing conceptual pieces and papers that are not based on empirical data). Applied Health Professions, Dentistry, Nursing and Pharmacy (UoA 3) has tended to be perceived as more sympathetic to bioethics research. Therefore, bioethics does not fit unproblematically into any of the current UoAs and bioethicists have been returned in the REF in a variety of units of assessment (UoAs) (ie, UoA 22 social work and social policy as well as the ones mentioned above).

\section{Recommendation}

Committees should be aware that the perceptions of lack of possible 'fit' into panels is not a problem specific to bioethics and this is a pressing problem confronting interdisciplinary research in general that needs to be addressed.

\section{Journal type}

Bioethicists often publish in their own journals, such as Journal of Medical Ethics, American Journal of Bioethics, Journal of Bioethical Inquiry and Bioethics. These journals may not be familiar to panels. There is a list of reputable journals created by Georgetown University: https://bioethics.georgetown.edu/2015/03/top200-most-cited-bioethics-articles-published-since-2009/ that can be consulted. It should be noted that impact factors for journals in medical ethics, the social sciences and humanities are generally much lower than those in some other disciplines (eg, medicine).

\footnotetext{
${ }^{\text {iv }}$ These refer to the unit of assessment (UoAs) in the 2014 REF.
}

\section{Recommendation}

Journals impact factors should be judged against the norms of the discipline. Good practice guidelines, such as the Leiden Manifesto that recognise that metrics are discipline specific, should be taken into account.

\section{Types of publication}

In bioethics, like other humanities and some social science disciplines, journal articles are only one form of valuable publication output and researchers also publish books and chapters in edited volumes. Their research is more commonly single authored than research in medicine, the life sciences and the social sciences, but more commonly co-authored than research in 'pure' philosophy and many other humanities disciplines. It is rarely done in large teams as is common in most laboratory-based disciplines.

Bioethicists often write on a wide variety of topics, frequently prompted by recent scientific, legal or social developments. Bioethicists also contribute to comment pieces, editorials, policy documents, and publish in other forums, particularly medical and professional journals and specialist subject journals.

\section{Recommendation}

The variety of publication forms and different platforms for publishing bioethics research should be recognised. Single-authored books can contribute significantly to the field and edited collections, and chapters in these, are valuable outputs which may be equivalent to a journal article, especially when published with a reputed publisher. ${ }^{\mathrm{vi}}$ Comment pieces should be judged in terms of their contribution to academic debate and can be important pieces that contribute to changes in practice and policy, and the impacts of these can be assessed.

\section{Research methods}

As bioethics is often concerned with conceptual and normative arguments, it is important to recognise that what is seen as 'research' in bioethics can encompass a range of methods and approaches: pieces that advance an argument; pieces that consider the ethical implications of developments; and also empirical pieces that involved data collection and analysis.

\section{Recommendation}

It should be recognised that research in bioethics encompasses a range of methods and approaches.

\section{Pace of publication}

Publication pace is also discipline specific. Given the type of research that bioethicists conduct an average productive output needs to be assessed relative to bioethics disciplinary norms.

\section{Recommendation}

The American Society for Bioethics and Humanities recommends 1.5-2 articles a year for junior academics (ASBH, 2009), but assessments of research quantity should take into account the researcher's home department/discipline, main publication venues/types and the extent of coauthorship.

\footnotetext{
v'Leiden Manifesto (http://www.nature.com/news/ bibliometrics-the-leiden-manifesto-for-research-metrics-1.17351).

${ }^{\mathrm{vi}}$ However, it must be recognised that there is debate over the status of book chapters and they are sometimes not seen as outputs of equal value to a journal article.
} 


\section{Authorship}

The ordering convention for authors differs between disciplines. In science, for example, the convention is that the first and last authors are the key authors. Alphabetical and 'descending order of contribution' are commonly used in bioethics, though the scientific model is also sometimes adopted. An increasing number of journals now require authors to specify their contributions to the manuscript.

\section{Recommendation}

Attention should be paid to how authors are ordered in different disciplines and what order represents what level of contribution. Panels should seek clarification on authorship norms used by applicants/candidates from bioethics, if necessary on an article-by-article basis.

\section{Grant capture}

As much of the work in bioethics is conceptual or normative, it does not always require grant support in the way traditional scientific research does. Though in many countries, including the UK, bioethics is well-funded relative to traditional humanities disciplines, there are normally fewer grants available in bioethics than in the medical sciences and those that exist tend to be of less monetary value than those in medically orientated disciplines.

\section{Recommendation}

Bioethicists should be judged on whether their research activity is of a comparable level to norms in their field ${ }^{\text {vii }}$ and whether they are making significant theoretical and/or practical contributions to their field.

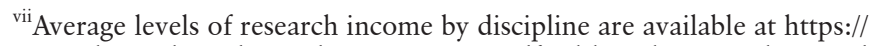
www.gla.ac.uk/media/media_544754_en.pdf. Although it must be noted that the use of these kind of metrics to monitor performance is contested.
}

\section{Teaching-research balance}

Bioethicists make a valuable contribution to a number of teaching programmes (eg, the medical undergraduate and postgraduate curriculum; law, social science, philosophy degrees) and other training forums. It is important that teaching, training and engagement with healthcare professionals is research-based and academics in this area are provided with the opportunities to carry out research to advance the discipline and provide an enhanced educational experience for students.

\section{Recommendation}

As part of recognising the importance of bioethics teaching, research in bioethics should be encouraged by recognising the value of this type of research and researchers given appropriate opportunities for career advancement.

Acknowledgements The authors would like to thank the IME Trustees for their input and support, the wider IME Research Committee and Professors Draper and Farsides who commented on a draft of this document.

Funding The authors have not declared a specific grant for this research from any funding agency in the public, commercial or not-for-profit sectors.

Disclaimer This statement presents the views of the authors. It has been endorsed by the Institute of Medical Ethics, but not by the authors' employing organisations or other organisations with or for which they work.

Competing interests The Institute of Medical Ethics co-owns and receives a share of the revenue from the Journal of Medical Ethics. TD is an editor of the Journal of Medical Ethics. All other authors have no competing interests to declare.

Provenance and peer review Not commissioned; internally peer reviewed.

(c) Article author(s) (or their employer(s) unless otherwise stated in the text of the article) 2018. All rights reserved. No commercial use is permitted unless otherwise expressly granted. 